\title{
Concentrações de ferro, cobre, zinco e manganês em equinos da raça Puro-sangue Lusitano, antes e após exercício ${ }^{1}$
}

\author{
Rodrigo A.B. Minini² ${ }^{2}$ Cecília B. Laposy ${ }^{3 *}$, Hemann B. Neto ${ }^{3}$, Alessandra Melchert ${ }^{4}$, \\ Rogério Giuffrida ${ }^{3}$, Hugo De Rossi ${ }^{5}$ e Heloisa F.D. do Valle ${ }^{5}$
}

\begin{abstract}
Minini R.A.B., Laposy C.B., Neto H.B., Melchert A., Giuffrida R., De Rossi H. \& Valle H.F.D. 2013. [Serum concentration of iron, copper, zinc and manganese in Pure-bred Lusitano horses, before and after exercise.] Concentrações de ferro, cobre, zinco e manganês em equinos da raça Puro-sangue Lusitano, antes e após exercício. Pesquisa Veterinária Brasileira 33(8):1045-1048. Programa de Mestrado em Ciência Animal, Universidade do Oeste Paulista, Pró-Reitoria de Pesquisa e Pós-Graduação-Unoeste, Rodov. Raposo Tavares Km 572, Bairro Limoeiro, Presidente Prudente, SP 19067-175, Brazil. E-mail: claposy@unoeste.br

In order to evaluate the sera concentrations of iron, copper, zinc and manganese trace minerals in thirty Pure-bred Lusitano athlete horses before and after exercise certified by clinical and laboratory assessments were studied. Blood samples were taken before and after 20 minutes of a dairy trot and gallop slight training, perfomed in a sandy floor ring, to measure the mineral concentrations, by atomic absorption spectrophotometry. It was observed that after exercising, the serum activity of iron did not change $(\mathrm{P}=0.2365)$, whereas copper values have significantly risen after training $(\mathrm{P}<0.001)$. On the other hand, zinc and manganese trace minerals decreased after exercise $(\mathrm{P}<0.001)$. In conclusion, it is possible to consider that the short time exercise may trigger sweating and consequently to change the serum concentration of iron, cooper, zinc and manganese in Pure-bred Lusitano athlete horses.
\end{abstract}

INDEX TERMS: Trace minerals, physical activity, athletic horses.

RESUMO.- 0 presente trabalho objetivou determinar a atividade sérica dos microminerais ferro, cobre, zinco e manganês em 30 equinos atletas da raça Puro-sangue Lusitano (PSL), antes e depois de exercícios, atestados por avaliações clínicas e laboratoriais. Amostras de sangue foram colhidas, antes e imediatamente após 20 minutos de exercício físico de trote e galope suaves realizados em pista de areia, para a realização das dosagens dos microminerais. A concentração dos microelementos foi determinada por espectrofotome-

\footnotetext{
${ }^{1}$ Recebido em 4 de março de 2013.

Aceito para publicação em 19 de julho de 2013

${ }^{2}$ Mestre em Ciência Animal, Universidade do Oeste Paulista (Unoeste), Pró-Reitoria de Pesquisa e Pós-Graduação-Unoeste, Rodov. Raposo Tavares Km 572, Bairro Limoeiro, Presidente Prudente, SP 19067-175, Brasil.

${ }^{3}$ Docentes, Programa de Mestrado em Ciência Animal, Unoeste, Pró-Reitoria de Pesquisa e Pós-Graduação-Unoeste, Rod. Raposo Tavares Km 572, Bairro Limoeiro. Presidente Prudente, SP.E-mails: rm.mv2007@gmail.com, hermann@unoeste.br, rgiuffrida@unoeste.br, hugodrossi@hotmail.com, lolovalle@bol.com.br.*Autor para correspondência: claposy@unoeste.br

${ }^{4}$ Docente, Departamento de Clínica Médica Veterinára, FMVZ, Unesp, Botucatu, SP 18618-970, Brasil. e-mail: alessandra@fmvz.unesp.br

${ }^{5}$ Discentes do Curso de Medicina Veterinária, Hospital Veterinário, Unoeste, Rodov Raposo Tavares Km 572, Bairro Limoeiro, Presidente Prudente, SP.
}

tria de absorção atômica. Observou-se que após o exercício, a atividade sérica de ferro não sofreu variações $(\mathrm{P}=0,2365)$, enquanto os valores de cobre se elevaram significativamente após o treinamento $(\mathrm{P}<0,001)$. Já o zinco e o manganês diminuíram após o exercício $(\mathrm{P}<0,001)$. Pode-se concluir que o exercício físico de curta duração pode gerar sudorese capaz de alterar as concentrações séricas de ferro, cobre, zinco e manganês em cavalos atletas da raça Puro-sangue Lusitano.

TERMOS DE INDEXAÇÃO: Microminerais, atividade física, equinos atletas.

\section{INTRODUÇÃo}

Nas últimas décadas, os criadores brasileiros, ao investir em melhoramento genético, obtiveram uma das mais seletas tropas de Puro-sangue Lusitanos (PSL). Atualmente, o país é o maior exportador da raça para a América do Norte e vem aumentando suas exportações para a Europa, inclusive para Portugal. No Brasil, existem cerca de 350 criadores com plantel de 10 mil animais, cuja maioria concentra-se no estado de São Paulo (Almeida Filho 2010).

0 interesse em avaliar ferro, cobre, zinco e manganês, relacionando-os com exercício baseia-se no fato de que estes 
minerais participam do metabolismo oxidativo e destruição dos peróxidos, tendo uma relação estreita na capacidade de oxigenação dos pulmões, no trabalho cardiovascular e no desempenho físico dos animais (Yur et al. 2008).

Vários estudos têm avaliado a concentração de microminerais em equinos submetidos à atividade física, como os verificados na raça Puro Sangue Inglês (Balarin 2002), Quarto de Milha e Mangalarga (Silva et al. 2007) e em cavalos de enduro (Haggett et al. 2010). Entretanto, estudos envolvendo elementros-traço em cavalos PSL são escassos na literatura.

Como base nestas premissas, este trabalho propõe-se a avaliar as concentrações séricas de ferro, zinco, cobre e manganês em animais Puro-sangue Lusitano atletas, antes e depois do exercício de trote e galope suaves.

\section{MATERIAL E MÉTODOS}

O ensaio foi realizado em um haras situado no município de Martinópolis, Estado de São Paulo, numa região de clima subtropical úmido com temperatura ambiente média de $260 \mathrm{C}$ e umidade relativa do ar de aproximadamente $86 \%$. Foram avaliados 30 equinos machos da raça PSL, não castrados, entre 3 e 5 anos de idade, com peso aproximado de $450 \mathrm{Kg}$. 0 presente estudo foi aprovado pelo Comitê de Ética em Pesquisa local, protocolada sob o número 226/09.

Como critério de inclusão, foram selecionados cavalos atletas hígidos mantidos sob uma rotina diária de exercícios físicos de trote e galope suaves. Para avaliação da higidez dos animais para inclusão e durante todo o estudo, foram realizadas a inspeção das mucosas aparentes, auscultação dos batimentos cardíacos e movimentos respiratórios, além de aferição da temperatura retal. Exames coproparasitológicos, hemograma, proteínas plasmáticas totais e pesquisa de hematozoários foram realizados com a finalidade de complementar a avaliação dos equinos, segundo Reed \& Bayly (2000).

Os animais foram alimentados seguindo a dieta preconizada na propriedade. com feno coast cross, ração peletizada TecHorse12 (Purina ${ }^{\circledR}$ ), administrados duas vezes ao dia, e suplemento mineral (Omolenefós70 Purina ${ }^{\circledR}$ ) uma vez ao dia.

Para avaliação da influência do exercício sobre as concentrações séricas dos microminerais, os animais foram submetidos a treinamento em pista de areia $(30 \times 50 \mathrm{~m})$. 0 tempo de atividade teve média de 20 minutos $( \pm 2,26)$ cronometrados (Cronômetro manual Casio ${ }^{\circledR}$ ). 0 horário (entre 8 e 11 horas da manhã) e o tempo de atividade física seguiu o protocolo pré-estabelecido pelo haras, a fim de não alterar o manejo dos animais. Os equinos foram sempre montados por um mesmo cavaleiro, e o conjunto cavaleiro e equipamento utilizado para montaria totalizou $82,0 \mathrm{Kg}$.

Amostras de $10 \mathrm{~mL}$ de sangue foram colhidas antes e imediatamente após o exercício, por punção venojugular, com auxílio de tubos a vácuo (Vacutainer ${ }^{\circledR}$ ) e agulhas de 25,0x8,0mm. Destes, 5 $\mathrm{mL}$ foram colhidos em tubos contendo anticoagulante (EDTA), para realização de hemograma (contador eletrônico SYSMEX-Roche), proteínas plasmáticas totais (refratometria) e pesquisa de hematozoários (esfregaço sanguíneo corado pelo método de Diff Quick), e outros $5 \mathrm{~mL}$ em recipientes siliconados sem anticoagulante, para obtenção de soro para dosagem dos minerais.

As concentrações séricas de ferro $(\mathrm{Fe})$, cobre $(\mathrm{Cu})$, zinco $(\mathrm{Zn})$ e manganês $(\mathrm{Mn})$ foram determinadas por espectrofotometria de absorção atômica, segundo Santarém (2004).

Os valores das dosagens séricas de cada mineral, antes e depois dos exercícios, foram transformados em escores padronizados da distribuição normal (escore Z), e comparados pelo teste t-pareado. Todas as análises foram realizadas por meio do pacote computacional Bioestat (Ayres et al. 2007), com nível de significância de 5\%.

\section{RESULTADOS}

O número total de hemácias (He), a concentração de hemoglobina (Hb), o hematócritos (Ht) e as proteínas plasmáticas totais (PPT) avaliados no presente ensaio aumentaram após a realização da atividade física, passando respectivamente de $8,85 \times 106 / \mu \mathrm{L} \pm 8,19$ para $9,35 \times 106 / \mu \mathrm{L}$ $\pm 10,51(\mathrm{P}<0,0436) ; 14,01 \mathrm{~g} / \mathrm{dL} \pm 1,03$ para $14,88 \mathrm{~g} / \mathrm{dL} \pm 1,23$

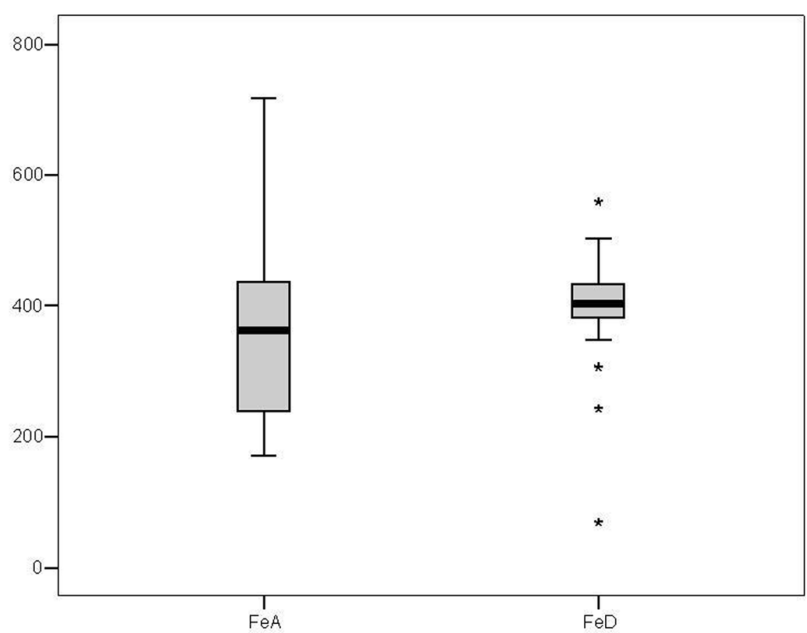

Fig.1. Concentrações séricas de ferro ( $\mu \mathrm{g} / \mathrm{dL}$ ) antes (FeA) e depois (FeD) do exercício em equinos da raça Puro-sangue Lusitano. As linhas no interior dos boxes denotam o segundo quartil (50\% dos dados - mediana); as linhas superiores, o terceiro quartil (75\% dos dados); e as inferiores, o primeiro quartil (25\% dos dados). As linhas externas ao boxe indicam os limites dos valores extremos, e os pontos externos a elas indicam os outliers.

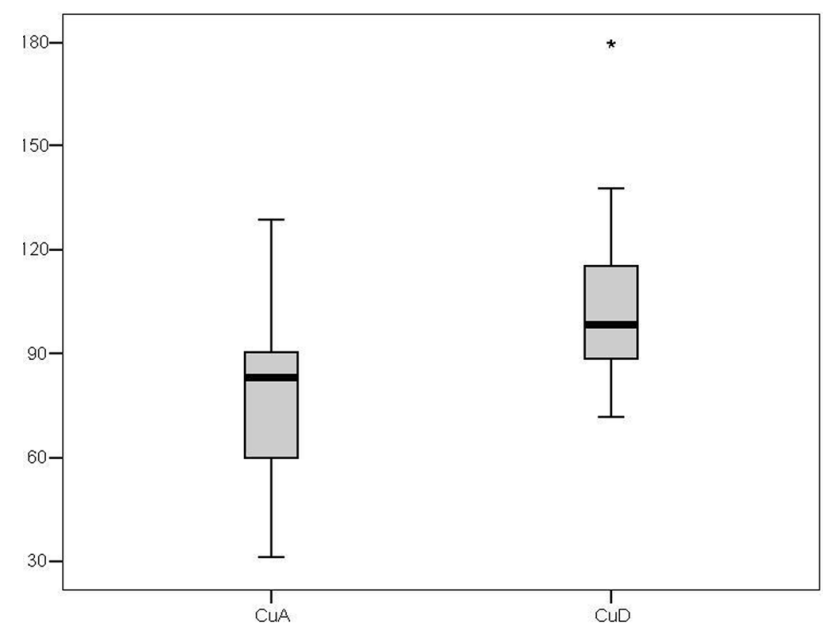

Fig.2. Concentrações séricas de cobre $(\mu \mathrm{g} / \mathrm{dL})$ antes $(\mathrm{CuA})$ e depois $(\mathrm{CuD})$ do exercício em equinos da raça Puro-sangue Lusitano. As linhas no interior dos boxes denotam o segundo quartil (50\% dos dados - mediana); as linhas superiores, o terceiro quartil (75\% dos dados); e as inferiores, o primeiro quartil (25\% dos dados). As linhas externas ao boxe indicam os limites dos valores extremos e os pontos externos a elas indicam os outliers. 


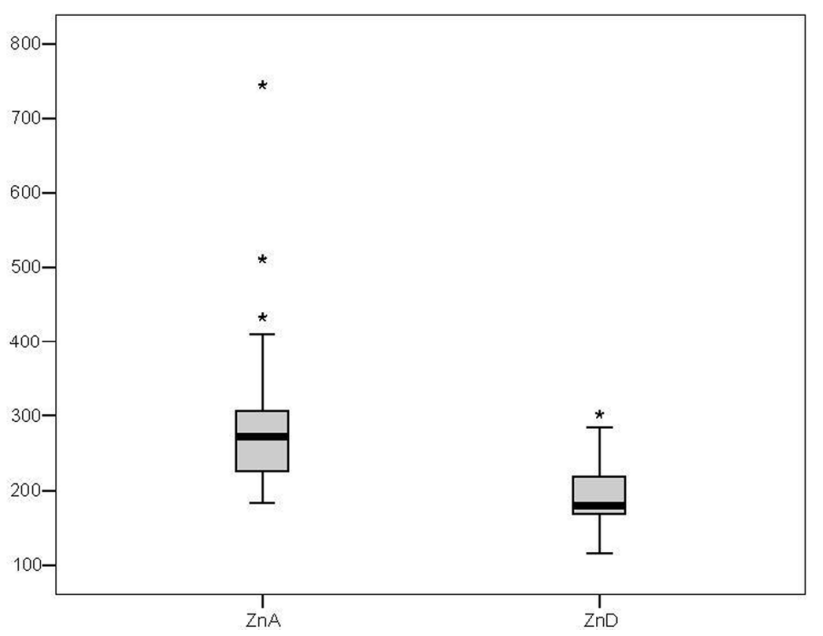

Fig.3. Concentrações séricas de zinco $(\mu \mathrm{g} / \mathrm{dL})$ antes $(\mathrm{ZnA})$ e depois (ZnD) do exercício em equinos da raça Puro-sangue Lusitano. As linhas no interior dos boxes denotam o segundo quartil (50\% dos dados - mediana); as linhas superiores, o terceiro quartil (75\% dos dados); e as inferiores, o primeiro quartil (25\% dos dados). As linhas externas ao boxe indicam os limites dos valores extremos e os pontos externos a elas indicam os outliers.

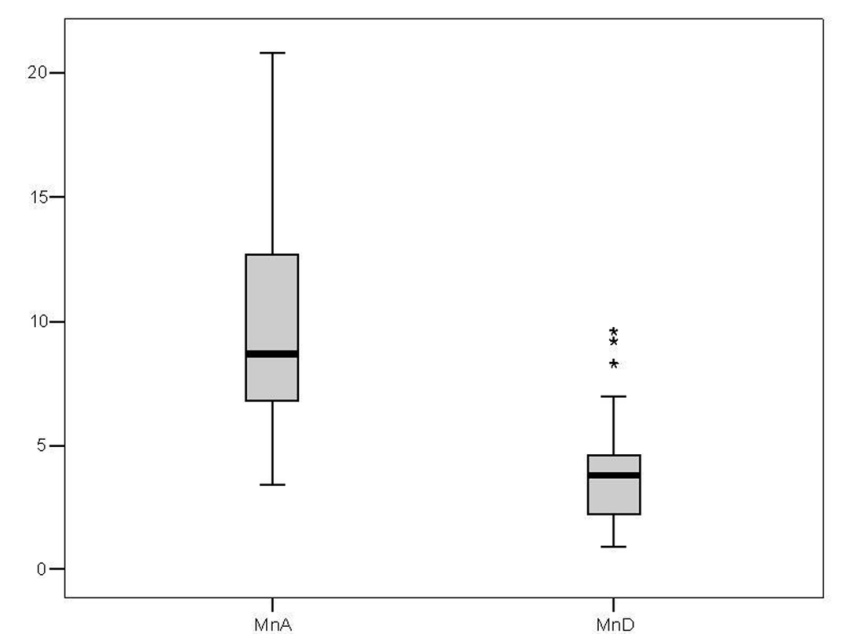

Fig.4. Concentrações séricas de manganês $(\mu \mathrm{g} / \mathrm{dL})$ antes $(\mathrm{MnA})$ e depois $(\mathrm{MnD})$ do exercício em equinos da raça Puro-sangue Lusitano. As linhas no interior dos boxes denotam o segundo quartil (50\% dos dados - mediana), as linhas superiores, o terceiro quartil ( $75 \%$ dos dados) e as inferiores o primeiro quartil ( $25 \%$ dos dados). As linhas externas ao box indicam os limites dos valores extremos e os pontos externos a elas indicam os outliers.

$(\mathrm{P}<0,0043) ; 39,09 \% \pm 3,10$ para $42,64 \% \pm 3,47(\mathrm{P}<0,0021)$ e de $6,31 \pm 0,23 \mathrm{~g} / \mathrm{dL}$ para $6,46 \pm 0,29 \mathrm{~g} / \mathrm{dL}(\mathrm{P}<0,0397)$. Os valores estavam dentro da faixa de normalidade para a espécie (Jain 1993).

Verificou-se que as mucosas aparentes de todos os animais passaram de normocoradas a congestas após a atividade física. A frequência cardíaca (FC) e respiratória (FR) aumentaram $(\mathrm{P}<0,0001)$ após o exercício $(57,7 \pm 11,6 \mathrm{bpm}$ e 46,5 $\pm 0,06 \mathrm{mpm}$, respectivamente), enquanto a temperatura retal (TR) média dos animais elevou-se $(38,7 \pm 0,060 \mathrm{C})$ $(\mathrm{P}=0,3327)$.
Nas Figuras 1 a 4 estão representadas os valores das concentrações séricas de $\mathrm{Fe}, \mathrm{Cu}, \mathrm{Zn}$ e $\mathrm{Mn}$, antes e depois do exercício dos PSL avaliados no presente estudo. Em relação às concentrações séricas de Fe (Fig.1), houve uma elevação $(P=0,2365)$ após o exercício $(398,32 \pm 85,54 \mu \mathrm{g} /$ $\mathrm{dL})$ quando comparadas ao momento anterior à atividade física $(362,91 \pm 134,13 \mu \mathrm{g} / \mathrm{dL})$. No caso do $\mathrm{Cu}$ (Fig.2) houve elevação $(\mathrm{P}<0,0001)$, passando de $75,69 \pm 23,56 \mu \mathrm{g} / \mathrm{dL}$ para $103,41 \pm 23,15 \mu \mathrm{g} / \mathrm{dL}$ ). Contraditoriamente, os valores séricos de Zn (Fig.3) e de Mn (Fig.4) diminuíram significativamente após o exercício físico. Os valores variaram de $294,85 \pm 119,52 \mu \mathrm{g} / \mathrm{dL}$ para $193,86 \pm 48,19 \mu \mathrm{g} / \mathrm{dL}(\mathrm{P}<0,0002)$ e de $9,91 \pm 4,37 \mu \mathrm{g} / \mathrm{dL}$ para $4,01 \pm 2,37 \mu \mathrm{g} / \mathrm{dL}(\mathrm{P}<0,0001)$, respectivamente, para $\mathrm{Zn}$ e $\mathrm{Mn}$.

\section{DISCUSSÃO}

A atividade física pode alterar vários parâmetros fisiológicos em equinos. 0 exercício pode induzir mudanças em parâmetros bioquímicos que são indicativos de estresse oxidativo (Dias et al. 2011). Estas alterações são exacerbadas quando os exercícios são praticados em condições de alta temperatura e umidade, como era o caso da região onde o nosso estudo foi realizado. Possivelmente, os fatores climáticos influenciaram na resposta térmica dos animais, gerando uma maior sudorese e perda de microelementos pelo suor. Titto et al. (2009) verificaram que cavalos Árabes em repouso, mantidos em diferentes condições de temperatura e umidade, tiveram as FC e FR aumentadas como um mecanismo para evitar o estresse térmico. Moura et al. (2011), ao analisar a termorregulação de cavalos anglo-árabes em exercícios de pista, verificaram que as condições ambientais afetaram diretamente o desempenho dos animais.

No presente estudo, houve aumento da FC e da FR acompanhado de elevação de He, Hb, Ht e PPT após o exercício de trote e galope suaves. Elevações tênues de Ht e PPT também foram observadas em cavalos submetidos ao mesmo tipo de atividade física que os animais do nosso estudo (Garcia et al. 1999) e também ao galope intenso (Paludo et al. 2002).

$\mathrm{O}$ aumento do Ht e das PPT pode caracterizar hemoconcentração causada provavelmente por contração esplênica, uma vez que o baço pode atuar como uma reserva cardiovascular para a manutenção do preenchimento ventricular em situações de FC alta, principalmente em casos de atividade física intensa (Veiga et al. 2006). Em cavalos árabes, foi observada uma relação entre a hemoconcentração e o aumento de $\mathrm{He}, \mathrm{Hb}$ e $\mathrm{Ht}$ nas primeiras horas de enduro, com retorno desses parâmetros aos valores basais após 24 horas (Teixeira-Neto et al. 2012). Os dados do presente estudo sugerem que a contração esplênica pode ocorrer também em animais submetidos a exercícios leves.

0 metabolismo de alguns minerais depende da intensidade e duração do exercício físico (Machado et al. 2010). Estudos têm associado a elevação nos níveis de $\mathrm{Fe}$ e $\mathrm{Cu}$ em equinos da raça PSI (Balarin 2002) e Anatoliano nativo (Yur et al. 2008), decorrente do exercício físico. A contração esplênica e a hemoconcentração provocada pela sudorese deve ter promovido a elevação sérica de $\mathrm{Fe}$ e $\mathrm{Cu}$ observada no presente estudo. Entretanto, Fernandes et al. (1999), em 
estudo com equinos de enduro, verificaram que os valores de Fe não se alteraram após realização de esforço. Sobretudo estes autores obtiveram as amostras de sangue para análise do mineral após seis horas do final do exercício, diferentemente do que foi proposto nesse estudo, quando as amostras foram colhidas imediatamente após a atividade física.

No caso do Zn, Hudson et al. (2001) verificaram que há uma maior necessidade deste mineral em animais que se exercitavam rotineiramente em relação àqueles que não praticavam atividade física regular. Balarin (2002), em estudo comparando a dosagem sérica de microminerais em PSI, verificou que após o galope de corrida em pista de areia na distância de $2000 \mathrm{~m}$, houve diminuição significativa nos valores de $\mathrm{Zn}$ nos equinos, dados estes que coincidem com os do presente estudo. Em equinos, a perda do mineral ocorre pelo suor, o que coincide com a redução moderada deste mineral na circulação e pode ser interpretada como sua redistribuição (Meyer 1985).

A diminuição da concentração sérica de Mn observada nos animais avaliados no nosso experimento esteve relacionada, provavelmente, ao importante papel do mineral em sistemas enzimáticos que catalisam a primeira etapa da síntese de carboidratos, além da remoção de superóxidos, que reduz os danos causados por radicais livres durante o exercício (Dias et al. 2011). Resultados similares foram encontrados por Balarin (2002) ao avaliar cavalos PSI antes e após exercício de alta intensidade.

De acordo com os resultados obtidos no presente estudo, realizado em ambiente de temperatura e umidade relativa altas, é possível considerar que o exercício físico de curta duração é suficiente para gerar sudorese e contração esplênica capazes de alterar as concentrações séricas de ferro, cobre, zinco e manganês em equinos da raça Puro-sangue Lusitano. Ademais, a atividade física pode influenciar diretamente a exigência de microelementos pelos equinos submetidos à rotina de atividade física de trote e galope suaves.

\section{REFERÊNCIAS}

Almeida Filho M.R.T. 2010. Tradição à vista. Disponível em <http// http:// www.privatebrokers.com.br/edicoes/artigo.asp?cod=189> Acesso em 20 jun. 2011.

Ayres M., Ayres Junior M., Ayres D.L. \& Santos A.S. 2007. Bioestat 5.0 - Aplicações estatísticas nas áreas das ciências biomédicas. ONG Mamiraua, Belém, PA. 364p.

Balarin M.R.S. 2002. Efeito do treinamento e de exercício de diferentes intensidades sobre os valores dos macro e microminerais, bioquímicos e hematológicos em equinos Puro-sangue Inglês (PSI), machos e fêmeas, dos 24 aos 36 meses de idade. Tese de Doutorado, Faculdade de Medicina Veterinária e Zootecnia, Universidade Estadual Paulista, Botucatu, SP. 111p.
Dias D.C.R., Rocha J.S., Mello F.M., El-Bachá R.S. \& Ayres M.C.C. 2011. Influência do exercício sobre o hemograma, enzimas marcadoras de lesão muscular e índice de peroxidaçãode biomoléculas em equinos submetidos à atividade de salto. Rev. Bras. Ciênc. Vet. 18(1):36-42.

Fernandes W.R., Souza M.C.C., Fava C., Mori E. \& Roncati N.V. 1999. Influência do exercício físico sobre os níveis séricos de ferro e de capacidade total de ligação do ferro em eqüinos de enduro. Vet. Notícias 5(2):79-82.

Garcia M., Guzman R., Cabezas I., Merino R., Palma C. \& Perez R. 1999. Evaluación del entrenamiento tradicional del caballo criollo chileno de rodeo mediante el análisis de variables fisiológicas y bioquímicas sanguíneas. Arch. Med. Vet. 31(2):212-228.

Haggett E., Magdesian K.G., Maas J., Puschner B., Higgins J. \& Fiack C. 2010. Whole blood selenium concentrations in endurance horses. Vet. J. 186(2):192-196.

Hudson C., Pagan J., Hoekstra K., Prince A., Gardner S. \& Geor R. 2001. Effects of exercise training on the digestibility and requirements of copper, zinc and manganese in Thoroughbred horses. Proc. $16^{\text {th }}$ Equine Nutrition and Physiology Society Sympposium, Lexington, Kentucky, p.138-140.

Jain N.C. 1993. Essentials of Veterinary Hematology. Lea and Febiger, Philadelphia. $417 \mathrm{p}$.

Machado L.P., Kohayagawa A., Yonezawa L.A., Silveira V.F. \& Saito M.E. 2010. Metabolismo do ferro em equinos atletas. Ciência Rural 40(3):703-711.

Meyer H. 1985. Nutrition of the equine athlete. $2^{\text {nd }}$ International Conference on Equine Exercise Physiology. San Diego, California, p.150.

Moura D.J., Maia A.P.A., Vercellino R.A., Medeiros B.B.L., Sarubi J. \& Griska P.R. 2011. Uso da termografia infravermelha na análise da termorregulação de cavalos em treinamento. Eng. Agríc., Jaboticabal, 31(1):23-32.

Paludo G.R., McManus C., Melo R.Q., Cardoso A.G., Mello F.P.S., Moreira M. \& Fuck B.H. 2002. Efeito do estresse térmico e do exercício sobre parâmetros fisiológicos de cavalos do Exército Brasileiro. Revta Bras. Zootec. 31(3):1130-1142.

Reed S.M. \& Bayly W.M. 2000. Medicina Interna Equina. Guanabara Koogan, Rio de Janeiro. 938p.

Santarém C.L. 2004. Valores séricos de macro e microminerais de equinos da raça Puro-Sangue Inglês (PSI), do nascimento até aos seis meses de idade. Tese de Doutorado, Faculdade de Medicina Veterinária e Zootecnia, Universidade Estadual Paulista, Botucatu, SP. 116p.

Silva M.A.M.L., Porto Filho R.M., Rosas Filho A.C., Maciel C.C., Doretto J.S. \& Silva H.L. 2007. Determinação das concentrações de cobre e zinco séricos de eqüinos da região de Espírito Santo do Pinhal. Bolm Med. Vet., Espírito Santo do Pinhal, 3(3):24-34.

Teixeira-Neto A.R., Ferraz G.H., Moscardini A.R.C., Albernaz R.M., Gondim M.R. \& Queiroz-Neto A. 2012. Do hematologic constituents really increase due to endurance exercise in horses? Pesq. Vet. Bras. 32(9):951-956.

Titto E.A.L., Pereira A.M.F., Toledo L.R.A., Passini R., Nogueira Filho J.C.M., Gobesso A.A.O., Etchichury M. \& Titto C.G. 2009. Concentração de eletrólitos em equinos submetidos a diferentes temperaturas. Revta Bras. Saúde Prod. Anim.10 (1):236-244.

Veiga A.P.M., Lopes S.T.A., Franciscato C., Oliveira L.S.S. \& Merini L.P. 2006. Valores Hematológicos, proteínas plasmáticas totais e fibrinogênio do cavalo crioulo: suas variações em relação ao sexo, idade e manejo. Acta Scient. Vet. 34(3):275-279.

Yur F., Dede S., Deger Y. \& Kilicalp D. 2008. Effects of vitamin E and selenium on serum trace and major elements in horses. Biol. Trace Elem. Res. 125(3):223-228. 